\title{
Classification of human and animal strains of Fusobacterium necrophorum by their pathogenic effects in mice
}

\author{
G. R. SMITH* and E. A. THORNTON \\ Institute of Zoology, The Zoological Society of London, Regent's Park, London NW1 $4 R Y$
}

\begin{abstract}
Forty-six strains of Fusobacterium necrophorum, 24 from animals and 22 of human origin, were examined by pathogenicity tests in mice, while the same strains were being examined in laboratories elsewhere by other methods. The pathogenicity tests consisted of (1) subcutaneous inoculation with a large dose of a pure culture, (2) subcutaneous inoculation with a small dose of $F$. necrophorum mixed with a large but relatively harmless dose of Staphylococcus aureus, and (3) intravenous inoculation with a large dose of a pure culture. Fourteen strains, all of animal origin, showed the characteristic behaviour of biotype A. Twenty-eight strains, 10 of animal origin and 18 from man, were classified as biotype B. The remaining four strains, all from man, produced a distinct type of infection in mice; these strains were referred to as 'A2433-like' because of their resemblance to a strain described in an earlier study. It would appear that biotype A strains, responsible for classical necrobacillosis in animals, do not infect man; that biotype $B$ strains occur in both man and animals; and that 'A2433-like' strains are probably confined to man.
\end{abstract}

\section{Introduction}

In an earlier study [1], eight human isolates of Fusobacterium necrophorum were examined by mouse inoculation techniques to compare their behaviour with that of animal isolates. The techniques used were (1) subcutaneous injection, (2) subcutaneous injection of inocula containing both $F$. necrophorum and a sublethal dose of Staphylococcus aureus, and (3) intravenous injection.

Animal strains are classified in two main biotypes, A and B, otherwise known as $F$. necrophorum subsp. necrophorum and $F$. necrophorum subsp. funduliforme, respectively [2-4]. An intermediate type, $A B$, has also been described $[2,5]$.

Mice inoculated subcutaneously with large doses $\left(>10^{6} \mathrm{cfu}\right)$ of pure cultures of biotype A strains die within $c .7$ days from necrotic lesions which spread rapidly from the injection site. The addition of sublethal numbers of certain bacteria (e.g., S. aureus,

Received 25 Feb. 1997; accepted 20 March 1997.

Corresponding author: Ms E. A. Thornton.

*Present address: Department of Pathology and Infectious Diseases, The Royal Veterinary College, Royal College Street, London NW1 0TU.
Escherichia coli, Actinomyces pyogenes) to the inoculum greatly enhances the infectivity of biotype A strains, reducing their minimum infective (lethal) dose by a factor of up to $10^{6}[6,7]$. Intravenous inoculation of mice with large doses of biotype A organisms results in death within a few days, with necrotic lesions in various sites, especially the liver, unless the course of the disease is too rapid to permit the development of macroscopic abnormalities [1].

Biotype B strains, injected subcutaneously in large doses, produce no more than a local lesion that heals quickly, and the inclusion of bacteria such as $S$. aureus in the inoculum does not appear to influence the infection $[1,8]$. In contrast, however, large doses of biotype $B$ strains given by the intravenous route usually produce purulent lesions, often severe, in the liver and elsewhere within 21 days; these are only occasionally associated with obvious general signs of illness, but they sometimes give rise to swellings on the body surface [1].

In the study of eight human strains referred to above [1], seven behaved in the manner typical of biotype B. The eighth strain (A2433), given subcutaneously in large doses, produced severe caseous lesions spreading from the injection site to involve most of the thickness of the thigh, and its minimum infective dose by the 
subcutaneous route was strikingly reduced by the presence of $S$. aureus in the inoculum; these two properties clearly distinguished strain A2433 from biotype B strains. Intravenous inoculation of strain A2433 in large doses gave rise to severe purulent lesions in the liver and elsewhere. However, the lesions produced by the subcutaneous or intravenous injection of strain A2433, unlike those produced by biotype A strains, did not give rise to a rapidly fatal outcome or to severe general signs of illness within the time span of the experiments ( 21 days). This strain therefore differed from both biotype A and biotype B.

The earlier study has now been extended by the work described here, in which 24 animal strains and 22 human strains of $F$. necrophorum were examined by the mouse inoculation techniques described above. Concurrently, the same strains were examined by several collaborating groups possessing special expertise in other techniques, whose results are published simultaneously with this paper $[9,10]$.

\section{Materials and methods}

These were described previously [1]. Only essential additional information and brief recapitulation of procedure are stated here.

\section{Organisms}

Of 24 animal strains of $F$. necrophorum, the following 20 were collected between Nov. 1981 and Aug. 1992 from animals in the Zoological Society's collections at Whipsnade and Regent's Park and from farm animals: A1 (peccary, abscess), A4 (antelope, head lesion), A10 (wallaby, jaw lesion), A19 (wallaby, spleen lesion), A42 (wallaby, facial lesion), A47 (wallaby, stomach lesion), A53 (mara, abscess), A62 (wallaby, foot lesion), A89 (wallaby, foot lesion), A102 (wallaby, jaw lesion), A117 (wallaby, head lesion), A146 (axis deer, faeces), A148 large colony (ox, central nervous system), A148 small colony (ox, central nervous system), A149 (bovine ruminal contents), A156 (kudu, faeces), A157 (oryx, faeces), A159 (wallaby, stomach contents), F2 (calf, faeces) and L7 (cattle litter). (The prefix 'A' in the strains listed above signifies 'anaerobe', and should not be taken to denote the biotype.) Three strains (AB2030, B2035 and B2079 - of biotypes AB, B and $B$, respectively), isolated from cattle in the USA [5], were supplied by Dr J. N. Berg; the first of these strains gave rise to two colonial types, which were designated strains $\mathrm{AB} 2030 \mathrm{R}$ and $\mathrm{AB} 2030 \mathrm{~S}$.

Twenty-two human strains, details of which are given in an accompanying paper [9], were designated $\mathrm{C} 412 /$ 92, C700/92, C775/92, C817/92, C1070/92, C1178/92, C1217/92, C13/93, C195/93, C202/93, C247/93, C289/ 93, C1153/93, 91723/90 (Luton), 699/91 (Luton), 12854/91 (Luton), 18911/91 (Luton), $28619 / 91$ (Lu- ton), 36114/91 (Luton), 54269/91 (Luton), 6834/91 (Luton) and NCTC10575.

The history of laboratory subculture was not known for most of the strains. For the purposes of the study, all strains were given code numbers (F1-F50) [9], and their true identity was not divulged to the participating workers until the studies had been completed.

\section{Mouse inoculation}

Cultures were grown in BM broth [11] for 24-48 h. A viable count was not obtained for the culture of strain A146, but cultures of the remaining 45 strains contained 72-2750 (mean 930) $\times 10^{6} \mathrm{cfu} / \mathrm{ml}$. For each strain, mice in groups of four were inoculated by three methods: (1) $0.1 \mathrm{ml}$ of neat culture injected subcutaneously on the outer aspect of the right thigh; (2) $0.1 \mathrm{ml}$ of diluted ( 1 in $10^{5}$ in a well-grown $\mathrm{BM}$ culture of $S$. aureus) culture, injected subcutaneously on the outer aspect of the right thigh; (3) $0.1 \mathrm{ml}$ of neat culture injected intravenously into a tail vein. The $S$. aureus cultures contained 240-975 (mean 558) $\times 10^{6} \mathrm{cfu} / \mathrm{ml}$; such cultures by themselves in doses of $0.1 \mathrm{ml}$ produced only mild ulcerating lesions which healed rapidly. Mice were observed for 19-21 days before being killed for post-mortem examination, unless prior euthanasia was necessitated by (1) the severity of illness, as was invariably the case with biotype A strains given by any of the three methods, or (2) obvious swellings or general signs of illness, which occasionally occurred in mice that received intravenous injections of strains other than those of biotype A.

It was expected that all strains tested would prove to be of biotype A or biotype B, or to be 'A2433-like', and that they would give rise to the characteristic effects already outlined (see Introduction) when injected into mice by the three methods described above.

\section{Results}

\section{Strains behaving as biotype $A$ in mouse tests}

Mouse pathogenicity characteristic of biotype A was shown by the following 14 strains (all from animals): A4 (F3, 49), A10 (F24), A42 (F38), A47 (F33), A53 (F34), A89 (F45), A102 (F25), A117 (F11), A146 (F5), A148 (F7, large colony), A149 (F20), A157 (F31), A159 (F28) and F2 (F39). Strain A89 (F45) was atypical in one respect; after intravenous inoculation, illness sufficiently severe to warrant euthanasia took 12-20 days to develop.

\section{Strains behaving as biotype $B$ in mouse tests}

The following 20 strains showed mouse pathogenicity which conformed completely with that expected of biotype B isolates: A1 (F41), A19 (F19, 23), A62 
(F43), A148 (F8, small colony), L7 (F36), B2035 (F1), A156 (F14), B2079 (F30) (all from animals); and C412/92 (F22), C817/92 (F15), C1217/92 (F44), C13/ 93 (F35), C195/93 (F27), C247/93 (F21), C289/93 (F2), 669/91 (Luton) (F6), 12854/91 (Luton) (F29), 18911/91 (Luton) (F42), 28619/91 (Luton) (F47), 36114/91 (Luton) (F37) (all from man).

The following eight strains, although showing mouse pathogenicity generally conforming with that of biotype $\mathrm{B}$, were considered atypical in one or more respects: AB2030R (F16), AB2030S (F46) (both from animals); and C775/92 (F9), C1153/92 (F26), 91723/ 90 (Luton) (F50), 6834/91 (Luton) (F13), 54269/91 (Luton) (F12), NCTC10575 (F10, 32) (all from man). These atypical attributes, which were often of a minor nature, are shown in Table 1.

\section{Strains behaving as 'A2433-like' in mouse tests}

Four strains - C700/92 (F4), C1070/92 (F18), C1178/ 92 (F48) and $\mathrm{C} 202 / 93$ (F17, 40) - all of human origin, fell into this category.

\section{Discussion}

Biotype A strains of $F$ necrophorum are responsible for severe necrotising infections in animals (necrobacillosis). Of the 46 isolates of $F$. necrophorum examined in this study, 14 were readily classified as biotype A by mouse pathogenicity; all except one, strain A89, behaved in a completely typical manner. The atypical feature of strain A 89 was considered to be minor. All 14 biotype A strains were of animal origin and there would seem to be no evidence that such strains affect man.
Four further strains were classified as 'A2433-like', because their mouse pathogenicity unequivocally resembled that of strain A2433, described in an earlier study [1]. So far, strains of this type have been isolated only from man.

The remaining 28 strains were classified as biotype B by their effects on mice. Of these, 20 (six from animals and 14 from man) behaved typically. However, eight were considered atypical, although often only slightly so, in one or more respects (Table 1). Six of the atypical strains were of human origin. The other two were two colonial variants of a single strain (AB2030) of bovine origin, isolated in the USA [5]; the original strain had been classified as biotype $A B$ because it had morphological characteristics of both biotypes A and B and fell between these two biotypes on the basis of direct haemagglutination of chicken erythrocytes and sedimentation in broth culture. $S$. aureus and a number of other bacterial species in sublethal doses greatly enhance the infectivity of biotype A strains $[6,7]$ and $S$. aureus had a similar effect on strain A2433 [1] and 'A2433-like' strains, but previous studies showed no comparable effect on the infectivity of biotype $\mathrm{B}$ strains [1, 8]. However, the results presented in Table 1 give rise to some suspicion that $S$. aureus influenced the infectivity of three of the strains classified by mouse inoculation as biotype $\mathrm{B}$ (AB2030R, AB2030S and NCTC10575), but further work would be needed to clarify this point.

\section{References}

1. Smith GR, Thornton EA. Pathogenicity of Fusobacterium necrophorum strains from man and animals. Epidemiol Infect 1993; 110: 499-506.

2. Fievez L. Étude comparée des souches de Sphaerophorus necrophorus isolées chez l'homme et chez l'animal. Brussels: Presses Academiques Européennes, 1963.

Table 1. Strains behaving as 'atypical' biotype B in mouse tests

\begin{tabular}{|c|c|c|c|}
\hline Strain no. & $\begin{array}{l}\text { Method }(1,2 \text { or } 3)^{*} \\
\text { of infection }\end{array}$ & $\begin{array}{l}\text { Numbers of mice affected } \\
\text { (in groups of four) }\end{array}$ & Atypical characteristics \\
\hline \multirow[t]{2}{*}{ AB2030R (F16) } & 1 & 4 & $\begin{array}{l}\text { Large }(1-2 \mathrm{~cm}) \text { local, superficial, ulcerating lesion } \\
\text { on day } 20\end{array}$ \\
\hline & 2 & 2 & As above \\
\hline \multirow{3}{*}{$\mathrm{AB} 2030 \mathrm{~S}(\mathrm{~F} 46)$} & 1 & 1 & Died on day 11 , with fibrinous peritonitis \\
\hline & 1 & 1 & $\begin{array}{l}\text { Large }(1 \mathrm{~cm}) \text {, local, superficial, healing lesion } \\
(\text { day } 20)\end{array}$ \\
\hline & 2 & 1 & $\begin{array}{l}\text { Large }(1.5 \mathrm{~cm}) \text { local, ulcerating superficial lesion } \\
(\text { day } 20)\end{array}$ \\
\hline C775/92 (F9) & 3 & 1 & Moribund on day 2 \\
\hline \multirow{2}{*}{ C1153/92 (F26) } & 3 & 1 & Died on day 9 \\
\hline & 3 & 3 & Died or moribund on day 13 \\
\hline 91723/90 (Luton) (F50) & 3 & 1 & Moribund on day 1 \\
\hline 6834/91 (Luton) (F13) & 3 & 2 & Died or moribund on day 3 \\
\hline 54269/91 (Luton) (F12) & 3 & 1 & Moribund on day 2 \\
\hline \multirow[t]{3}{*}{ NCTC $10575(\mathrm{~F} 10,32)$} & 2 & 1 & $\begin{array}{l}\text { Died on day } 8 \text { with large }(1 \mathrm{~cm}) \text { local, superficial } \\
\text { lesion }\end{array}$ \\
\hline & 2 & 1 & $\begin{array}{l}\text { Large }(1.5 \times 3 \mathrm{~cm}) \text { local superficial lesion present } \\
\text { on day } 20\end{array}$ \\
\hline & 3 & 2 & Died on day 9 or 11 \\
\hline
\end{tabular}

\footnotetext{
${ }^{*} 1$, Subcutaneous; 2 , subcutaneous, with $S$. aureus; 3 , intravenous.
} 
3. Beerens H, Fievez, L, Wattre P. Observations concerning 7 strains of Sphaerophorus necrophorus, Sphaerophorus funduliformis and Sphaerophorus pseudonecrophorus species. [Observations concernant 7 souches appertenant aux espèces Sphaerophorus necrophorus, Sphaerophorus funduliformis, Sphaerophorus pseudonecrophorus.] Ann Inst Pasteur 1971; 121: $37-41$.

4. Shinjo T, Fujisawa T, Mitsuoka T. Proposal of two subspecies of Fusobacterium necrophorum (Flugge) Moore and Holdeman: Fusobacterium necrophorum subsp. necrophorum subsp. nov., nom. rev. (ex Flugge 1886), and Fusobacterium necrophorum subsp. funduliforme subsp. nov., nom. rev. (ex Halle 1898). Int $J$ Syst Bacteriol 1991; 41: 395-397.

5. Berg JN, Scanlan CM. Studies of Fusobacterium necrophorum from bovine hepatic abscesses: biotypes, quantitation, virulence, and antibiotic susceptibility. Am $J$ Vet Res 1982; 43: $1580-1586$.

6. Smith GR, Till D, Wallace LM, Noakes DE. Enhancement of the infectivity of Fusobacterium necrophorum by other bacteria. Epidemiol Infect 1989; 102: 447-458.

7. Smith GR, Barton SA, Wallace LM. Further observations on enhancement of the infectivity of Fusobacterium necrophorum by other bacteria. Epidemiol Infect 1991; 106: 305-310.

8. Smith GR. Pathogenicity of Fusobacterium necrophorum biovar B. Res Vet Sci 1992; 52: 260-261.

9. Hall V, Duerden BI, Magee JT, Ryley HC, Brazier JS, A comparative study of Fusobacterium necrophorum strains from human and animal sources by phenotypic reactions, pyrolysis mass spectrometry and SDS-PAGE. $J$ Med Microbiol 1997; 46: $865-871$.

10. Brown R, Lough HG, Poxton IR. Phenotypic characteristics and lipopolysaccharides of human and animal isolates of Fusobacterium necrophorum. J Med Microbiol 1997; 46: 873878 .

11. Deacon AG, Duerden BI, Holbrook WP. Gas-liquid chromatographic analysis of metabolic products in the identification of Bacteroidaceae of clinical interest. $J$ Med Microbiol 1978; 11: 81-99. 